\title{
Obtenção e análise de cerâmicas porosas com a incorporação de produtos orgânicos ao corpo cerâmico
}

\section{(Obtaining and analysis of porous ceramic with the incorporation of organic products to the ceramic body)}

\author{
R. P. S. Dutra, L. R. de Araújo Pontes \\ Departamento de Tecnologia Mecânica - DTM \\ Universidade Federal da Paraíba - UFPB \\ Laboratório de Materiais e Produtos Cerâmicos - LMPC \\ Centro de Tecnologia, Campus I, João Pessoa, PB, Brasil, 58059-900 \\ lmpc@lsr.ct.ufpb.br; rpsd@bol.com.br
}

\begin{abstract}
Resumo
As cerâmicas porosas possuem um elevado potencial para serem usadas em diversas aplicações importantes. Combinando adequadamente matérias-primas e técnicas de processamento, é possível obter cerâmicas porosas com elevados valores de resistência mecânica, resistência ao ataque químico, elevada refratariedade e elevada uniformidade estrutural. Entre os vários métodos de obtenção de cerâmica porosa, o método de incorporação de produtos orgânicos ao corpo cerâmico é bastante utilizado quando se deseja trabalhar com a porosidade do produto. No entanto, muitas variáveis devem ser analisadas, a começar pela quantidade de material orgânico adicionado ao corpo cerâmico. Este trabalho tem como objetivo a elaboração de cerâmicas porosas com a incorporação do pó-de-madeira ao corpo cerâmico e a análise das propriedades físicas e mecânicas deste material com a variação da temperatura de processamento. Os resultados indicaram que o método é viável, constatando um aumento da fração de poros com a adição do material orgânico e boa resistência mecânica do material.
\end{abstract}

Palavras-chave: argila, pó-de-madeira, porosidade, resistência mecânica.

\begin{abstract}
The porous ceramic have a high potential to be used in several important applications. Combining raw materials with processing techniques appropriately is possible to obtain porous ceramic with high values of mechanical resistance, resistance to the chemical attack, high refratariety and high structural uniformity. Among the several methods of obtaining porous ceramic, the method of incorporation organic products of the ceramic body is very used when wish work with the porosity of the product. However, many variety should be analyzed, to begin the amount of organic material added to the ceramic body. This work has as objective the elaboration of porous ceramic with the incorporation of the wood powder to the ceramic body and the analysis of the physical and mechanical properties of this material with the variation of the processing temperature. The results indicated that the method is viable, verifying an increase of the fraction of pores with the addition of the organic material and good mechanical resistance of the material.
\end{abstract}

Keyword: clay, wood-powder, porosity, mechanical resistance.

\section{INTRODUÇÃO}

As cerâmicas porosas possuem um elevado potencial para serem usadas em diversas aplicações importantes, tais como: filtros, catalisadores, isolantes térmicos, materiais para proteção contra fogo, queimadores de gás, entre outros. Combinando adequadamente as matérias-primas e as técnicas de processamento, é possível obter cerâmicas porosas com elevados valores de resistência mecânica, resistência ao ataque químico, elevada refratariedade e elevada uniformidade estrutural. São estas propriedades que as tornam apropriadas para uma variedade de aplicações, nas quais as tensões térmicas e mecânicas não permitem o uso de materiais metálicos ou poliméricos [1].

Existem vários métodos para obtenção de cerâmicas porosas. O método da esponja polimérica consiste na introdução da pasta cerâmica numa esponja. Após secagem, a esponja é removida por uma operação de queima e o material é sinterizado, resultando em um material com porosidade aberta. Outra técnica comum é o método espumante, cujo agente espumante é adicionado na suspensão cerâmica. Por agitação, é produzida uma espuma a qual, após remoção da fase líquida, constrói uma estrutura de poro e consiste essencialmente em poros fechados [2]. Um dos primeiros métodos desenvolvidos, e que ainda hoje é largamente usado, consiste na incorporação de produtos orgânicos dentro dos corpos cerâmicos, os quais são removidos durante a queima, deixando poros cujo tamanho está relacionado com o tamanho das partículas dos agentes orgânicos. Cada método tem as suas vantagens e usos potenciais. Contudo, o controle do processamento e, consequentemente as propriedades finais dos materiais, são um problema geral [1].

Há dois tipos de poros: abertos e fechados [3]. Os poros abertos, também chamados de poros interligados, são aqueles 
que têm contato com a superfície externa do material, sendo bastante útil na fabricação dos filtros cerâmicos. Na fabricação de materiais isolantes é importante ter um grande número de poros fechados, ou seja, poros isolados. Esses poros isolados possuem em seu interior ar que constitui o poder isolante do material.

Na técnica de preparação de cerâmicas porosas pela incorporação de produtos orgânicos ao corpo cerâmico, a formação dos poros vai depender da maneira como o material orgânico ficou situado ao corpo, ou seja, podemos ter poros abertos e poros fechados.

Este trabalho tem como objetivo a elaboração de cerâmicas porosas com a incorporação do pó-de-madeira ao corpo cerâmico e a análise das propriedades físicas e mecânicas destes corpos com a variação do processamento para sua obtenção.

\section{MATERIAISE MÉTODOS}

Para obtenção das cerâmicas porosas, partiu-se da caracterização de uma argila natural até a determinação das propriedades dos corpos-de-prova porosos, conforme o esquema a seguir:

Para fabricação das cerâmicas porosas com a incorporação dos produtos orgânicos ao corpo cerâmico é importante a caracterização dos materiais, principalmente do material que vai funcionar como estrutura do produto, neste caso, a argila.

a) argila: foi recebida no laboratório em sacos de pano totalizando, aproximadamente, $20 \mathrm{Kg}$. A amostra total foi espalhada sobre sacos de pano e deixada durante a noite. No dia seguinte, a amostra total foi seca em estufa a $110^{\circ} \mathrm{C}$ por $24 \mathrm{~h}$.

b) amostragem: a amostra total foi homogeneizada e passou pelo processo de quarteamento, do qual $2 \mathrm{Kg}$ foram separados para os ensaios físicos e químicos e o restante da amostra colocado em um saco plástico para os ensaios tecnológicos.

c) ensaios iniciais: a análise granulométrica foi desenvolvida de acordo com a norma ABNT NBR 7181 [4]. Este método consiste na análise granulométrica por peneiramento, a qual predomina o uso das peneiras ABNT e a análise granulométrica por sedimentação, que determina a velocidade de queda das partículas. O limite de liquidez marca a mudança do estado líquido para o estado plástico à medida que a argila vai perdendo umidade e adquirindo consistência, ou vice-versa. Enquanto que o limite de plasticidade marca a mudança entre os estados plásticos e sólidos. Estes limites são denominados de limites de Atterberg e foram determinados pelas normas ABNT NBR 7180 [5] e NBR 6459 [6], respectivamente. A determinação da densidade real foi realizada pela norma do departamento nacional de estradas e rodagens (DNER) ME 093/94 [7]. O método consiste em determinar o volume do material sólido de massa conhecida, excluindo todos os poros, dentro de um picnômetro de $30 \mathrm{~mL}$. Já a análise química foi realizada segundo o método clássico das determinações gravimétricas e volumétricas contidos nas referências [8-10]. Para a análise por difração de raios $X$, foi utilizado um difratômetro de raios X Siemens modelo D5000 com radiação $\mathrm{CuK} \alpha$ e velocidade do goniômetro de $0,02^{\circ}(2 \theta)$ por passo, com tempo de contagem de $1 \mathrm{~s}$ por passo. A interpretação foi efetuada por comparação com padrões

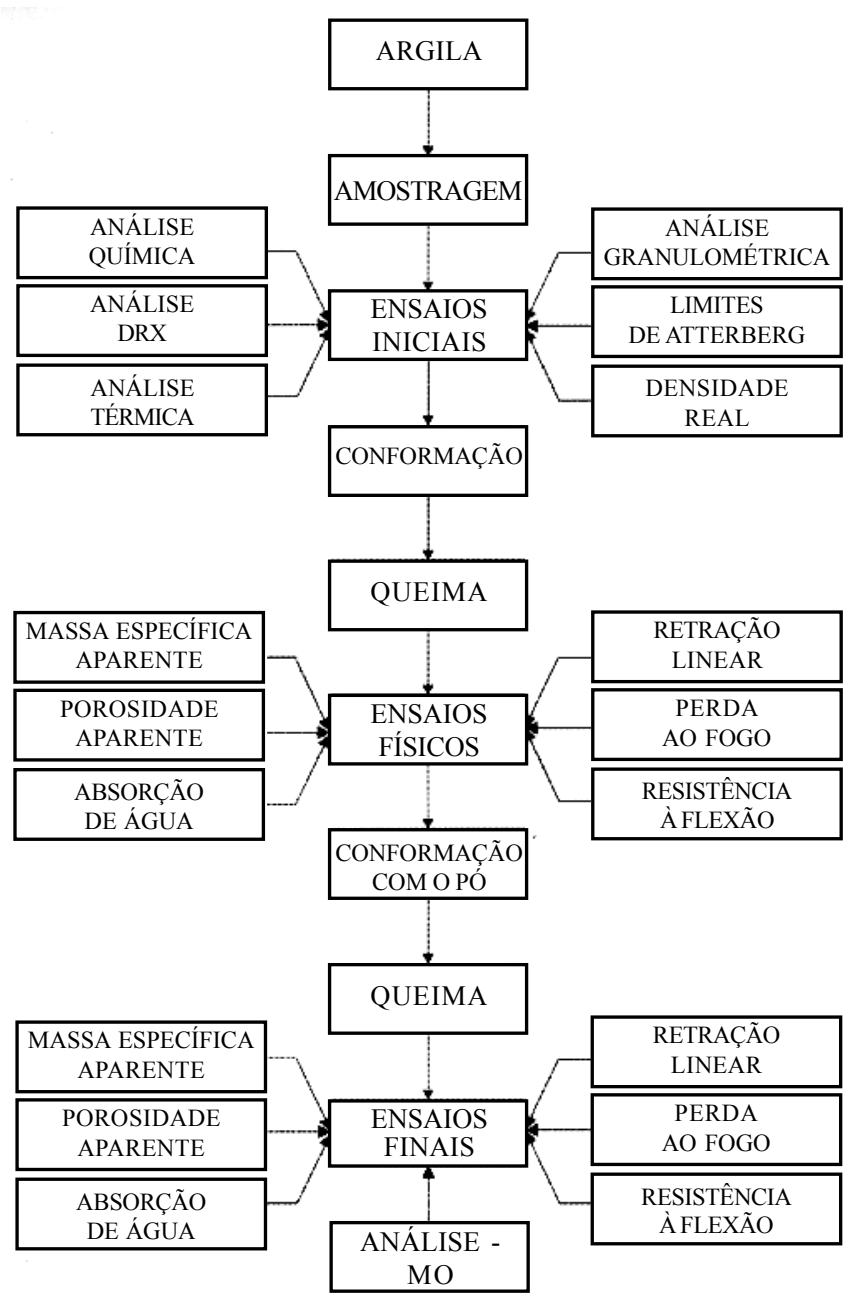

Figura 1: Esquema das etapas para a obtenção de cerâmicas porosas. [Figure1: Schematic details to obtain porous ceramic.]

contidos no software Siemens Diffrac (EVA). Esse ensaio foi realizado no Laboratório de Solidificação Rápida - UFPB, Campus I. A análise térmica foi realizada no Laboratório de Análise Térmica e Termoquímica - UFPB, Campus I. O equipamento usado foi o SDT 2960 Simultaneous DSC-TGA, TA Instruments.

d) conformação: os corpos-de-prova de perfil retangular de 6 x 2 x 0,5 cm foram moldados sob pressão de $2400 \mathrm{Kgf} / \mathrm{cm}^{2}$, numa prensa uniaxial, pesando-se $13 \mathrm{~g}$ da argila que passou na peneira $A B N T N^{\circ} 80$ (abertura $0,18 \mathrm{~mm}$ ).

e) queima: após secagem na estufa elétrica à $110^{\circ} \mathrm{C}$ por 24 $\mathrm{h}$, os corpos-de-prova foram queimados em um forno elétrico Nabertherm, com taxa de aquecimento de $300{ }^{\circ} \mathrm{C} / \mathrm{h}$ e patamar final de $1 \mathrm{~h}$. As temperaturas finais foram de 950, 1150, $1250 \mathrm{e}$ $1450{ }^{\circ} \mathrm{C}$, e o resfriamento foi realizado no próprio forno durante toda noite.

f) ensaios físicos e mecânicos: os ensaios físicos foram realizados de acordo com a sistemática proposta por SOUSA SANTOS [11], com a única exceção da queima e medida das propriedades na temperatura de $1150^{\circ} \mathrm{C}$. A porosidade aparente (PA), a absorção de água (AA) e a massa específica aparente (MEA) foram determinadas pelo método de Arquimedes. Nesse método, os corpos-de-prova são imersos em água destilada em 
ebulição, e deixados por $2 \mathrm{~h}$. Após esfriarem são feitas medidas do peso saturado $\left(\mathrm{P}_{\mathrm{SAT}}\right)$ e do peso imerso $\left(\mathrm{P}_{\mathrm{I}}\right)$ em uma balança analítica hidrostática. Inicialmente, é medido o peso seco $\left(\mathrm{P}_{\mathrm{S}}\right)$ dos corpos-de-prova. O cálculo dessas propriedades foi determinado pelas seguintes equações:

$$
\begin{aligned}
& \operatorname{PA}(\%)=\frac{P_{S A T}-P_{S}}{P_{S A T}-P_{I}} * 100 \\
& \operatorname{AA~}(\%)=\frac{P_{S A T}-P_{S}}{P_{S A T}} * 100 \\
& \operatorname{MEA}\left(\mathrm{g} / \mathrm{cm}^{3}\right)=\frac{P_{S A T}}{P_{S A T}-P_{I}} * 100
\end{aligned}
$$

O comportamento do material durante a queima pode ser avaliado mediante a variação de sua retração linear $(R L)$ e da sua perda de massa ao fogo (PF) em função da temperatura, sendo determinadas pelas equações (D) e (E):

$$
\begin{aligned}
& \mathrm{RL}(\%)=\frac{L_{S}-L_{Q}}{L_{Q}} * 100 \\
& \operatorname{PF}(\%)=\frac{P_{S}-P_{Q}}{P_{Q}} * 100
\end{aligned}
$$

onde: $\mathrm{L}_{\mathrm{S}}$ é o comprimento inicial da peça após a etapa de moldagem e $\mathrm{L}_{\mathrm{Q}}$ o comprimento da peça após a etapa de queima. $\mathrm{P}_{\mathrm{S}}$ é o peso da peça seca e $\mathrm{P}_{\mathrm{Q}}$ o peso da peça queimada.

A resistência à flexão (RF) expressa a tensão máxima em um material não-dúctil como sendo na fibra externa, num carregamento em três pontos. Neste caso, a resistência mecânica se calcula a partir da equação $(\mathrm{F})$ :

$$
\mathrm{RF}(\mathrm{MPa})=\frac{3 F L}{2 b d^{2}}
$$

onde, F é a força de ruptura, b e d são as dimensões de seção transversal e L é a distância entre os apoios.

g) conformação com o pó: o pó-de-madeira foi proveniente de uma marcenaria de João Pessoa e foi passado na peneira ABNT No40 (abertura 0,42 mm) e misturado manualmente nas seguintes proporções: $10,20,30 \%$ em peso, adicionado a argila. A conformação dos corpos-de-prova foi realizada da mesma maneira e com os mesmos instrumentos da primeira conformação (item d).

h) queima: antes da queima os corpos-de-prova foram secos em estufa à $110^{\circ} \mathrm{C}$ por $24 \mathrm{~h}$. A queima foi realizada em um forno elétrico MAITEC, em uma atmosfera oxidante, taxa de aquecimento de $120^{\circ} \mathrm{C} / \mathrm{h}$ e temperaturas de 1100,1150 e $1200^{\circ} \mathrm{C}$.

i) ensaios finais: a microscopia ótica foi realizada no Laboratório de Instrumentação Ótica do Departamento de Física da UFPB, Campus I, utilizando-se um microscópio ótico da marca OLYMPUS CBB com uma mini câmara acoplada. Todos os demais ensaios seguiram a sistemática do item f) deste trabalho.

\section{RESULTADOS E DISCUSSÃO}

Análise granulométrica: as partículas sólidas constituintes nas matérias-primas cerâmicas possuem uma grande variedade de formas e tamanhos e podem apresentar em diferentes estados de agregação [12]. A distribuição do tamanho de partículas, junto a outras características como forma e estado de agregação, determina as propriedades do produto acabado e regulam o comportamento da pasta durante o processo de fabricação [13].

A Fig. 2 mostra o gráfico da análise granulométrica da argila estudada. Foi determinada, segundo a ABNT, uma fração argila

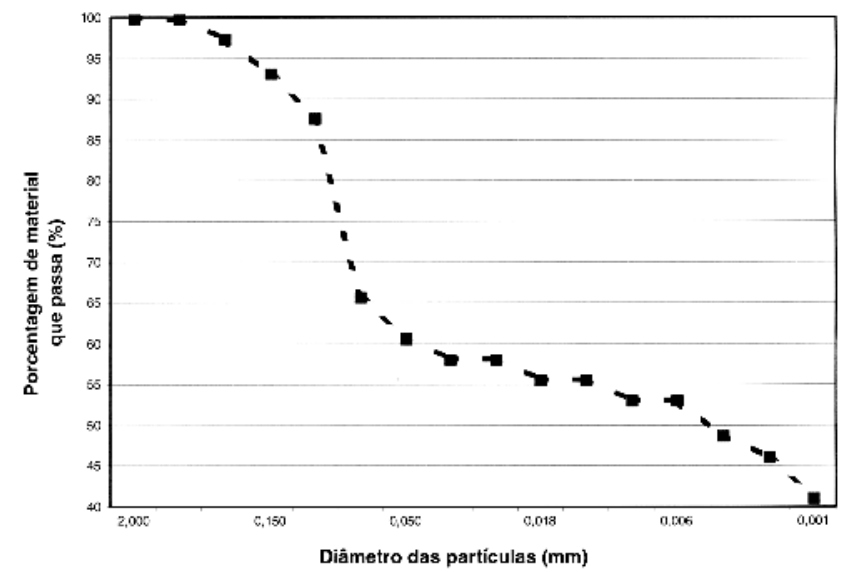

Figura 2: Curva da distribuição granulométrica da argila.

[Figure 2: Particle-size distribution of the clay.]

de $48,73 \%$. Enquanto a fração silte, areia e pedregulho foram de $13,27 \%, 37,96 \%$ e $0,04 \%$, respectivamente.

Limites de Atterberg: os materiais argilosos apresentam partículas finas que proporcionam uma grande plasticidade, tanto maior quanto menor é seu tamanho. Segundo Caputo [14], para os solos em cuja textura haja uma certa porcentagem de fração fina, não basta a granulométria para caracterizá-los, pois suas propriedades plásticas dependem do teor de umidade, além da forma das partículas e da sua composição química e mineralógica.

A argila apresentou um índice de plasticidade de 21,00\%, resultante da diferença do limite de liquidez $(48,69 \%)$ pelo limite de plasticidade $(27,60 \%)$.

Densidade real: a densidade do solo varia de acordo com a composição e a mineralogia de suas partículas. Essa propriedade, além de ser usada para controlar a quantidade de aglomerantes, faz-se necessária para execução da medida da área específica.

O valor da densidade real para a argila estudada foi de 2,62 $\mathrm{g} / \mathrm{cm}^{3}$, determinada a partir da média de três determinações, com desvio relativo máximo de $2 \%$ e com aproximações de duas casas decimais.

Análise química: do resultado da análise química, que se 
dá em forma de porcentagem em peso dos óxidos (Tabela I), pode-se obter as seguintes informações: o conteúdo de óxido de silício $\left(\mathrm{SiO}_{2}\right)$ é devido, possivelmente, à caulinita, às micas, aos feldspatos e aos quartzos. A quantidade de óxido de alumínio $\left(\mathrm{Al}_{2} \mathrm{O}_{3}\right)$ pode ser relacionada ao argilomineral caulinita e ao feldspato. Já o óxido de cálcio $(\mathrm{CaO})$ e o óxido de magnésio $(\mathrm{MgO})$ são, geralmente, provenientes da calcita, dolomita e gipsita. O óxido de potássio $\left(\mathrm{K}_{2} \mathrm{O}\right)$ e o óxido de sódio $\left(\mathrm{Na}_{2} \mathrm{O}\right)$ são álcalis encontrados nas argilas devido aos feldspatos, à mica e à ilita.

Análise - DRX: a Fig. 3 mostra o difratograma dos

Tabela I - Análise química da argila.

[Table I - Chemical analysis of the clay.]

\begin{tabular}{lc}
\hline Constituintes & Teor $(\%)$ \\
\hline $\mathrm{PR}$ (perda ao rubro) & 10,15 \\
\hline $\mathrm{SiO}_{2}$ (óxido de silício) & 54,56 \\
\hline $\mathrm{RI}$ (resíduo insolúvel) & 2,48 \\
\hline $\mathrm{Fe}_{2} \mathrm{O}_{3}$ (óxido de ferro) & 5,95 \\
\hline $\mathrm{Al}_{2} \mathrm{O}_{3}$ (óxido de alumínio) & 24,58 \\
\hline $\mathrm{CaO}$ (óxido de cálcio) & Traços \\
\hline $\mathrm{MgO}$ (óxido de magnésio) & Traços \\
\hline $\mathrm{Na}_{2} \mathrm{O}$ (óxido de sódio) & 0,98 \\
\hline $\mathrm{K}_{2} \mathrm{O}$ (óxido de potássio) & 1,04 \\
\hline
\end{tabular}

argilominerais contidos na argila. Por ter apresentado distância interplanar basal de 7,19 $\AA$, essa argila pertence ao grupo das caulinitas. Através das comparações feitas com os padrões contidos no software EVA, constatou-se que os argilominerais predominantes foram a caulinita e a nacrita. Observamos, também, picos referentes ao mineral quartzo.

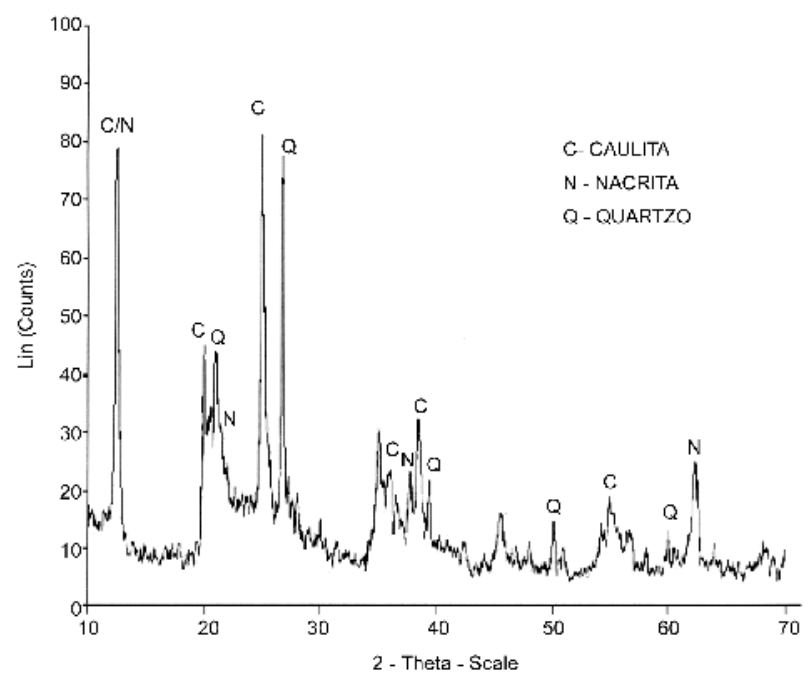

Figura 3: Difratograma de raios $X$ da argila.

[Figure 3: X-ray diffraction pattern of the clay.]
Análise térmica: a Fig. 4 representa as curvas da análise termogravimétrica e da análise térmica diferencial da argila. A interpretação que se pode realizar a partir dessas curvas é a seguinte: (1) a temperaturas inferiores a $200{ }^{\circ} \mathrm{C}$ se produz a eliminação da água livre. Essa água se encontra adsorvida sobre a superfície das partículas finas da caulinita. Nessa faixa de temperatura, mais precisamente a $80^{\circ} \mathrm{C}$, aparece o primeiro pico endotérmico; (2) entre as temperaturas de $200^{\circ} \mathrm{Ce} 500^{\circ} \mathrm{C}$ ocorreu, possivelmente, a oxidação da matéria orgânica, com suave perda de massa; (3) entre as temperaturas de $450^{\circ} \mathrm{Ce} 650^{\circ} \mathrm{C}$ ocorreram reações endotérmicas e perda de massa devido a desidroxilação (eliminação dos íons $\mathrm{OH}^{-}$da estrutura cristalina) dos argilominerais. Essa reação produz um pico endotérmico na curva da ATD na proximidade de $530{ }^{\circ} \mathrm{C}$; (4) o único pico exotérmico aparece ao $980^{\circ} \mathrm{C}$. Este é um pico característico das argilas cauliníticas. A natureza das fases desenvolvidas nesta reação exotérmica não está totalmente esclarecida, existindo

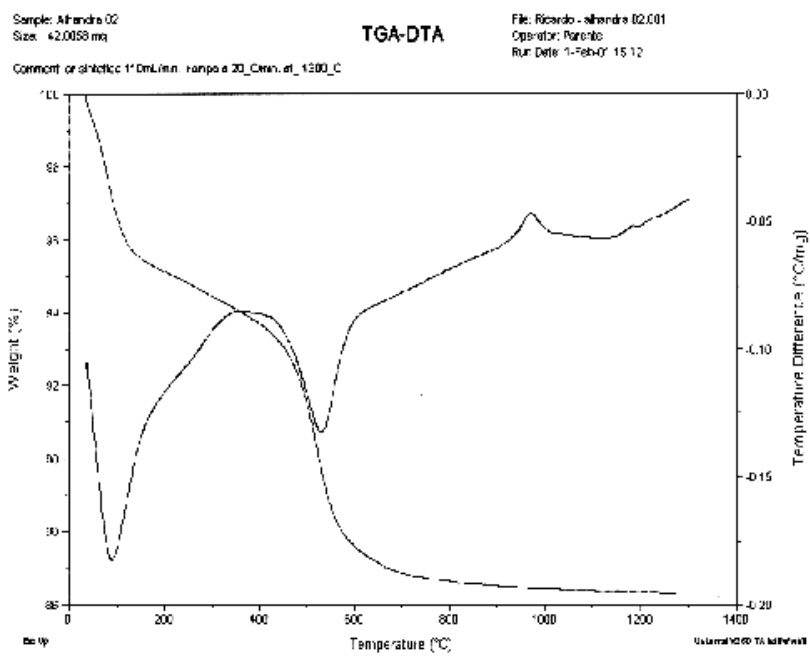

Figura 4: Curvas TG e ATD da argila.

[Figure 4: TG and DTA curves of the clay.]

Tabela II - Resultados experimentais: porosidade aparente (PA), absorção de água (AA), massa específica aparente (MEA), retração linear $(\mathrm{RL})$, perda ao fogo $(\mathrm{PF})$ e resistência à flexão (RF) dos corpos-de-prova.

[Table II - Experimental results: apparent porosity, absorption of water, apparent specific mass, linear retraction, fire loss and flexure resistance of the proof bodies.]

\begin{tabular}{lllllll}
\hline $\begin{array}{l}\mathrm{T} \\
\left({ }^{\circ} \mathrm{C}\right)\end{array}$ & $\begin{array}{l}\mathrm{PA} \\
(\%)\end{array}$ & $\begin{array}{c}\text { AA } \\
(\%)\end{array}$ & $\begin{array}{c}\text { MEA } \\
\left(\mathrm{g} / \mathrm{cm}^{3}\right)\end{array}$ & $\begin{array}{l}\mathrm{RL} \\
(\%)\end{array}$ & $\begin{array}{l}\mathrm{PF} \\
(\%)\end{array}$ & $\begin{array}{l}\mathrm{RF} \\
(\mathrm{MPa})\end{array}$ \\
\hline 950 & 32,74 & 14,63 & 1,53 & 1,96 & 9,99 & 12,9 \\
\hline 1150 & 24,18 & 10,73 & 2,01 & 7,70 & 10,50 & 19,1 \\
\hline 1250 & 17,93 & 7,65 & 2,16 & 10,48 & 10,01 & 24,8 \\
\hline 1450 & 12,84 & 5,99 & 2,01 & 8,24 & 10,57 & 86,1 \\
\hline
\end{tabular}


Tabela III - Resultados experimentais: perda ao fogo (PF) e retração linear (RL) dos corpos-de-prova. [Table III - Experimental results: fire loss and linear retraction of the proof bodies.]

\begin{tabular}{lccccccc}
\hline Temperaturas & \multicolumn{2}{c}{$1100^{\circ} \mathrm{C}$} & \multicolumn{2}{c}{$1150{ }^{\circ} \mathrm{C}$} & \multicolumn{2}{c}{$1200^{\circ} \mathrm{C}$} \\
\hline Propriedades & & $\mathrm{PF}(\%)$ & $\mathrm{RL}(\%)$ & $\mathrm{PF}(\%)$ & $\mathrm{RL}(\%)$ & $\mathrm{PF}(\%)$ & $\mathrm{RL}(\%)$ \\
\hline Misturas & $0 \%$ & 10,10 & 5,14 & 10,96 & 7,79 & 13,24 & 9,44 \\
\cline { 2 - 8 } & $10 \%$ & 19,49 & 5,64 & 21,28 & 7,93 & 23,27 & 9,57 \\
\cline { 2 - 8 } & $20 \%$ & 29,11 & 5,78 & 31,38 & 8,70 & 30,47 & 10,16 \\
\cline { 2 - 8 } & $30 \%$ & 38,92 & 6,42 & 42,04 & 8,85 & 38,96 & 10,13 \\
\hline
\end{tabular}

Tabela IV - Resultados experimentais: porosidade aparente (PA) e absorção de água (AA) dos corpos-de-prova. [Table IV - Experimental results: apparent porosity and absorption of water of the proof bodies.]

\begin{tabular}{lccccccc}
\hline Temperaturas & \multicolumn{2}{c}{$1100{ }^{\circ} \mathrm{C}$} & \multicolumn{2}{c}{$1150{ }^{\circ} \mathrm{C}$} & \multicolumn{2}{c}{$1200{ }^{\circ} \mathrm{C}$} \\
\hline Propriedades & & PA $(\%)$ & AA $(\%)$ & PA (\%) & AA (\%) & PA (\%) & AA (\%) \\
\hline Misturas & $0 \%$ & 28,13 & 12,79 & 22,16 & 9,64 & 17,51 & 7,41 \\
\cline { 2 - 8 } & $10 \%$ & 34,77 & 18,61 & 34,74 & 16,86 & 30,98 & 14,69 \\
\cline { 2 - 8 } & $20 \%$ & 50,88 & 25,33 & 44,82 & 23,65 & 41,67 & 21,45 \\
\cline { 2 - 8 } & $30 \%$ & 54,86 & 31,30 & 51,71 & 29,01 & 49,47 & 27,12 \\
\hline
\end{tabular}

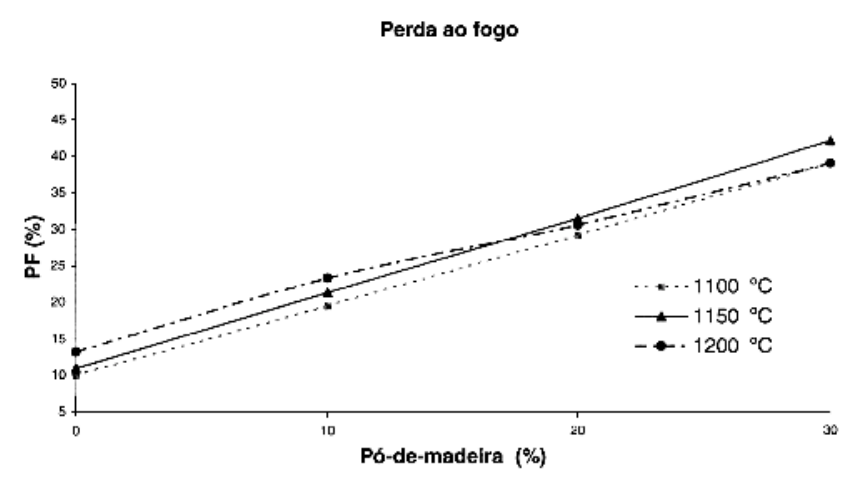

(a)

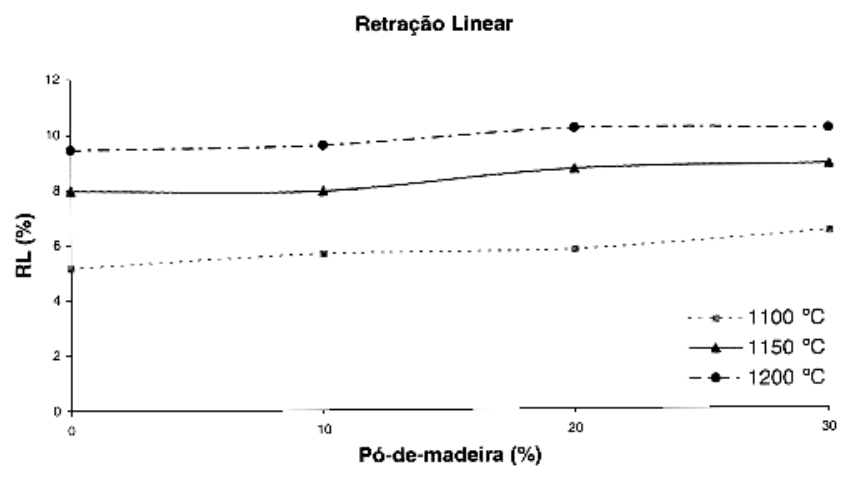

(b)

Figura 5: Curva da perda ao fogo (a) e curva da retração linear (b) em função da quantidade de pó.

[Figure 5: Fire loss (a) and linear retraction (b) as a function of the powder quantity.]

uma grande controvérsia, centrada principalmente na identidade da fase cúbica que se forma.

Ensaios finais: na Tabela II são apresentados os resultados da massa específica aparente (MEA), da porosidade aparente (PA), da absorção de água (AA), da retração linear (RL), da perda ao fogo $(\mathrm{PF})$ e da resistência à flexão (RF) dos corpos-deprova queimados.

A Tabela III apresenta os resultados da perda ao fogo (PF) e da retração linear (RL) dos corpos-de-prova após mistura com o pó-de-madeira e queima nas temperaturas de $1100^{\circ} \mathrm{C}$, $1150^{\circ} \mathrm{C}$ e $1250^{\circ} \mathrm{C}$. A medida em que se aumenta a quantidade de pó-de-madeira à argila, tem-se um pequeno aumento desses parâmetros.

O comportamento da perda ao fogo e da retração linear em relação à variação de temperatura podem ser comparados (Fig. 5).

Na Tabela IV são apresentados os resultados da porosidade aparente (PA) e da absorção de água (AA) com relação à quantidade de pó-de-madeira e da temperatura de queima. Observa-se na Fig. 6 que com o aumento da percentagem do pó-de-madeira, tanto a porosidade quanto a absorção tiveram um aumento progressivo.

A massa específica aparente (MEA) e a resistência à flexão 
Tabela V - Resultados experimentais: massa específica aparente (MEA) e resistência à flexão (RF) dos corpos-de-prova. [Table $V$ - Experimental results: apparent specific mass and flexure resistance of the proof bodies.]

\begin{tabular}{cccccccc}
\hline Temperaturas & & \multicolumn{2}{c}{$110{ }^{\circ} \mathrm{C}$} & \multicolumn{2}{c}{$1150{ }^{\circ} \mathrm{C}$} & \multicolumn{2}{c}{$1200^{\circ} \mathrm{C}$} \\
\hline Propriedades & & MEA & RF & MEA & RF & MEA & RF \\
\hline \multirow{3}{*}{ Misturas } & & $\left(\mathrm{g} / \mathrm{cm}^{3}\right)$ & $(\mathrm{MPa})$ & $\left(\mathrm{g} / \mathrm{cm}^{3}\right)$ & $(\mathrm{MPa})$ & $\left(\mathrm{g} / \mathrm{cm}^{3}\right)$ & $(\mathrm{MPa})$ \\
\cline { 2 - 8 } & $0 \%$ & 1,92 & 25,0 & 2,08 & 37,7 & 2,19 & 52,1 \\
\cline { 2 - 8 } & $10 \%$ & 1,52 & 19,7 & 1,71 & 32,5 & 1,80 & 34,2 \\
\cline { 2 - 8 } & $20 \%$ & 1,50 & 8,4 & 1,45 & 18,1 & 1,53 & 22,6 \\
\cline { 2 - 8 } & $30 \%$ & 1,20 & 4,7 & 1,27 & 11,7 & 1,33 & 15,0 \\
\hline
\end{tabular}

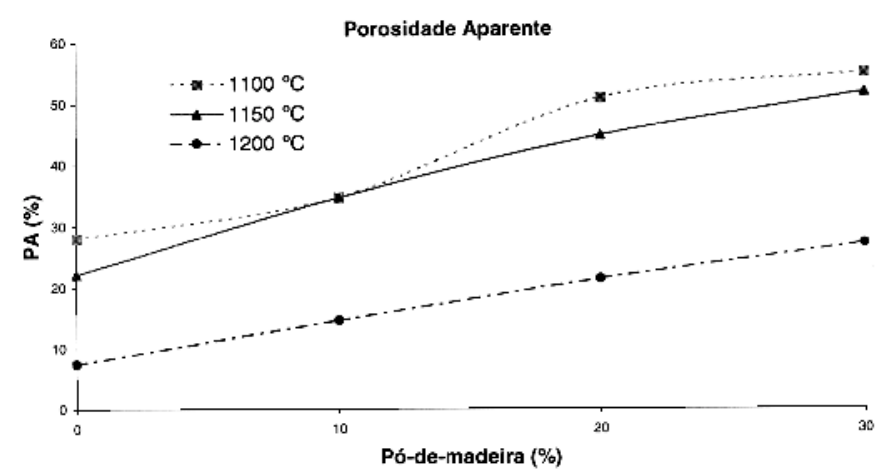

(a)

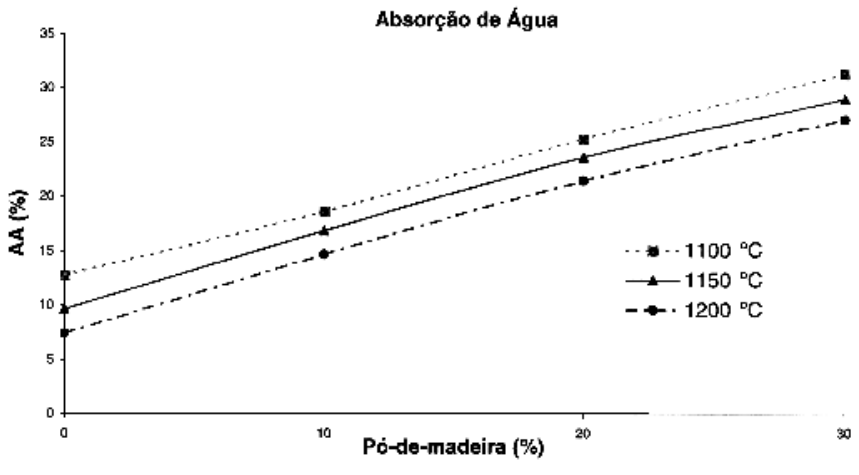

(b)

Figura 6: Curva da porosidade aparente (a) e curva da absorção de água (b) em função da quantidade de pó.

[Figure 6: Apparent porosity (a) and water absorption (b) as a function of the quantity of powder.]

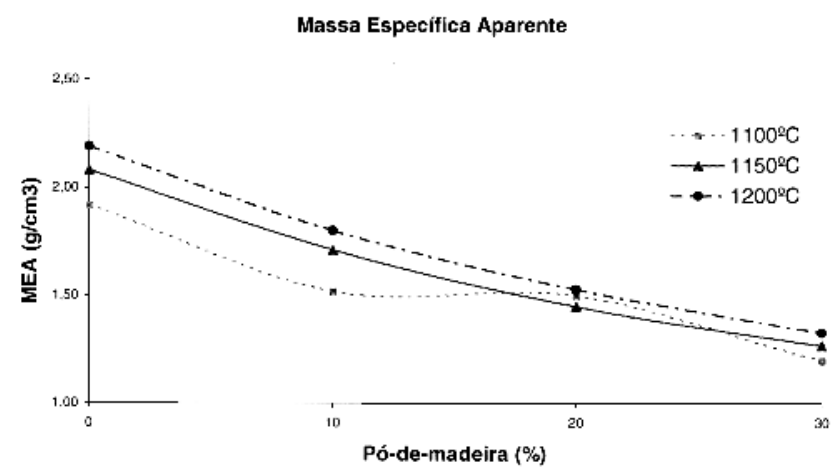

(a)

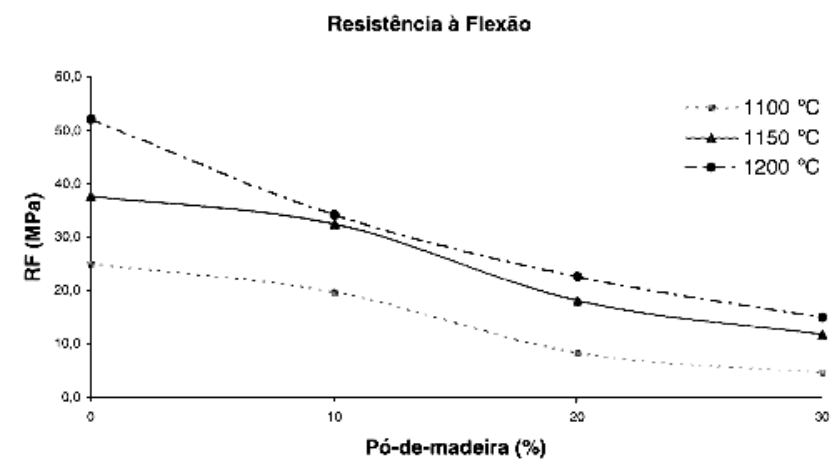

(b)

Figura 7: Curva da massa especifica aparente (a) e curva da resistência à flexão (b) em função da quantidade de pó.

[Figure 7: Apparent specific mass (a) and flexure resistance (b) as a function of powder quantity.]

(RF) estão diretamente relacionadas, de modo que, quando se aumenta a quantidade de pó-de-madeira diminui a MEA e a RF. É importante observar na Tabela V e na Fig. 7 o fator temperatura para essas propriedades.
Na Fig. 8 são apresentadas as fotografias referentes a microscopia ótica. Pode-se visualizar o aumento da quantidade e tamanho dos poros na medida em que a quantidade do produto orgânico é aumentada. 

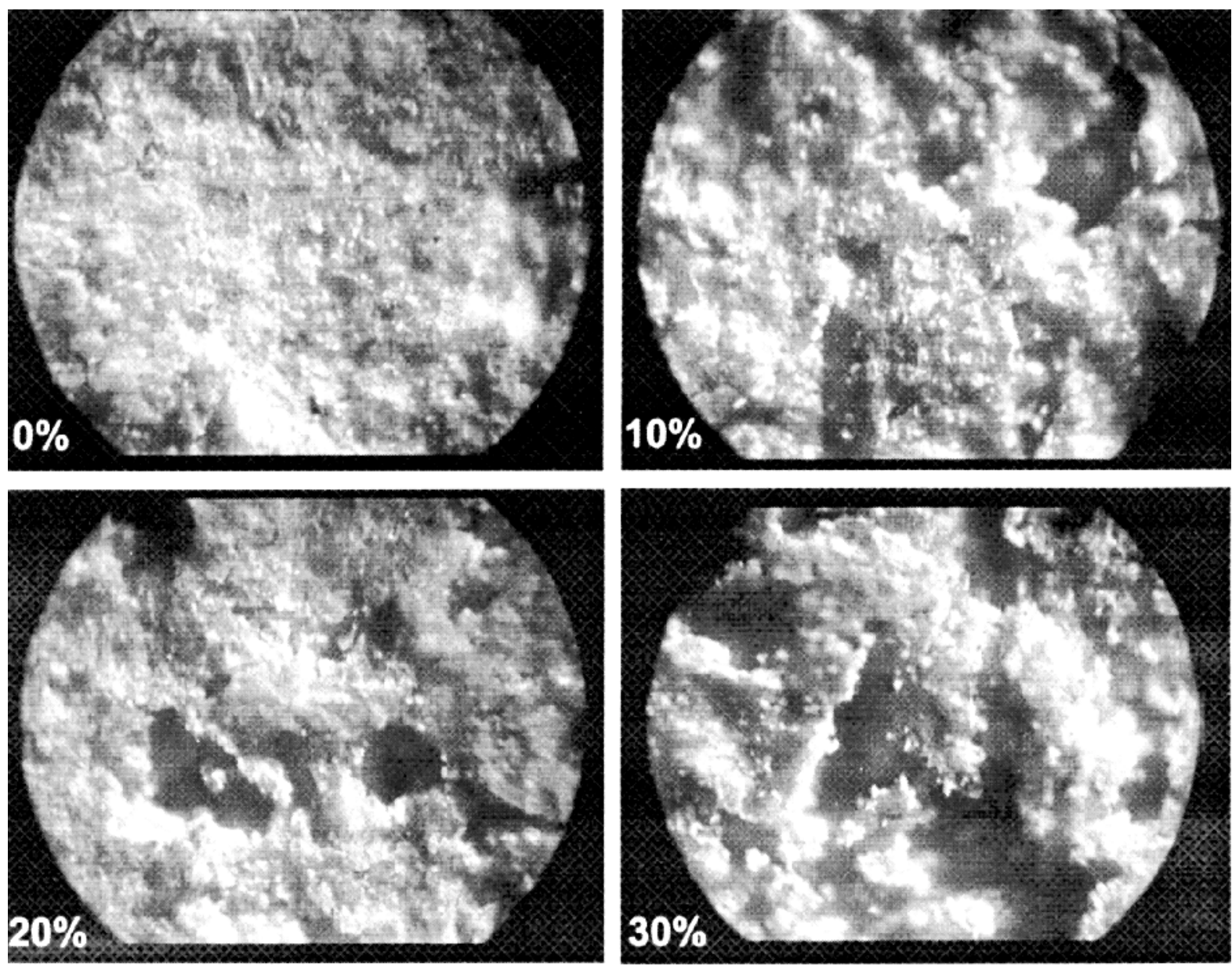

Figura 8: Micrografias ópticas do material poroso.

[Figure 8: Optical micrographs of the porous material.]

\section{CONCLUSÕES}

Foi comprovado que a incorporação de produtos orgânicos ao corpo cerâmico para a obtenção de cerâmicas porosas é um dos vários métodos que possibilitam uma alteração na estrutura do material. Entretanto, não é possível um controle quanto à formação dos poros no corpo cerâmico, ou seja, neste método podem aparecer tantos poros fechados como poros abertos, dependendo da maneira como o material orgânico ficou localizado na matriz. Com isso, impossibilita uma indicação imediata para uso do material poroso, ou seja, são necessários ensaios específicos como, por exemplo, a condutividade térmica, no caso de uso do material como isolador térmico.

Quanto à análise das propriedades físicas e mecânicas em relação à temperatura, foi constado que na medida em que esta aumenta, a porosidade aparente e a absorção de água diminuem, enquanto a massa específica aparente e a resistência à flexão aumentam. Dessa maneira, a temperatura é uma das variáveis no processo de obtenção das cerâmicas porosas, cabendo para futuros trabalhos análise de outras variáveis como, por exemplo, o patamar final de sinterização.

\section{AGRADECIMENTOS}

Os autores agradecem a CAPES pelo apoio financeiro; às
Profas. Ieda M. G. Santos, do Departamento de Química, UFPB, Lucianna Gama, do Departamento de Engenharia de Materiais, UFCG; aos professores Paulo C. de Oliveira, do Departamento de Física, UFPB e Severino Jackson, do Departamento de Tecnologia Mecânica, UFPB; a Renata, aluna de IC do curso de Engenharia de Materiais; e aos técnicos Delby Filho, Euclides Nunez e Itânio Veloso pelas suas colaborações.

\section{REFERÊNCIAS}

[1] A. F. Lemos, J. M. F. Ferreira, Anais do $45^{\circ}$ Congresso Brasileiro de Cerâmica, Florianópolis, S.C. (2001).

[2] J. S. Cintra Jr., W. N. do Santos, J. Eur. Ceram. Soc. 20 (2000) 1871.

[3] Van Vlack, L. Hall, Propriedades dos Materiais Cerâmicos, Editora Edgard Blucher, S. Paulo, Brasil (1973) p. 220.

[4] NBR - 7181, ABNT, "Solo - Análise granulométrica" (1984). [5] NBR - 7180, ABNT, "Solo - Determinação do limite de plasticidade" (1984).

[6] NBR - 6459, ABNT, "Solo - Determinação do limite de liquidez"(1984).

[7] ME 085/94, "Solos - determinação da densidade real" (1994). [8] Técnicas e Métodos 12, Métodos de análise química adotados para a certificação de amostras padrão de calcário, IPT, São Paulo (1981). 
[9] S. L. Moro, P. Santini, Cerâmica 12, 47-48 (1978) 203.

[10] P. Santini, S. L. Moro, Métodos de análise química adotado no IPT, Publicação 771 do Instituto de Pesquisas Tecnológicas do Estado de S. Paulo, S. Paulo (1967).

[11] P. Sousa Santos, Tecnologia de Argilas, Editora Edgard Blücher, Vol. I, S. Paulo, Brasil (1989).

[12] A Barba et al., Materias primas para la fabricación de soportes de baldosas cerámicas, Instituto de Tecnología Cerámica, Espanha (1997) p. 138.

[13] R. P. S. Dutra, L. R. A. Pontes, Anais do $45^{\circ}$ Congresso Brasileiro de Cerâmica, Florianópolis, S.C. (2001).

[14] H. P. Caputo, Mecânica dos Solos e suas Aplicações, Livro Técnico, Vol.1, Rio de Janeiro, Brasil (1994).

(Rec. 29/04/02, Ac.26/07/02) 